\title{
A New Homatropine Potentiometric Membrane Sensor as a Useful Device for Homatropine Hydrobromide Analysis in Pharmaceutical Formulation and Urine: a Computational Study
}

\author{
Mohammad Reza Ganjali, ${ }^{*, a}$ Zahra Memari, ${ }^{a}$ Siavash Riahi, ${ }^{a, b}$ Farnoush Faridbod, ${ }^{a}$ \\ Parviz Norouzi ${ }^{a}$ and Manesha A. K. Sian ${ }^{a}$ \\ ${ }^{a}$ Center of Excellence in Electrochemistry, Faculty of Chemistry, University of Tehran, Tehran, Iran \\ ${ }^{b}$ Institute of Petroleum Engineering, Faculty of Engineering, University of Tehran, Tehran, Iran
}

\begin{abstract}
Homatropina ("Equipin, Isopto Homatropine") é um medicamento anticolinérgico que inibe receptores muscarínicos de acetilcolina e, consequentemente, o sistema nervoso parassimpático.É encontrado na forma de sal, bromoidrato ou metilbrometo. Neste estudo, foi construído um sensor potenciométrico de membrana líquida para determinação rápida e simples de bromoidrato de homatropina em formulações farmacêuticas e em urina. Para a preparação da membrana, complexos homatropina-tetrafenilborato foram empregados como materiais eletroativos na membrana. $\mathrm{O}$ sensor proposto apresenta um intervalo linear amplo $\left(10^{-5}-10^{-1} \mathrm{~mol} \mathrm{~L}^{-1}\right)$, baixo limite de detecção $\left(8 \times 10^{-6} \mathrm{~mol} \mathrm{~L}^{-1}\right)$, e resposta rápida $(c a .10 \mathrm{~s})$. A validação do método mostra que os sensores são adequados para aplicação em análises de controle de qualidade de bromoidrato de homatropina em formulações farmacêuticas e urina.
\end{abstract}

Homatropine (Equipin, Isopto Homatropine) is an anticholinergic medication that inhibits muscarinic acetylcholine receptors and thus the parasympathetic nervous system. It is available as the hydrobromide or methylbromide salt. In this study, a potentiometric liquid membrane sensor for simple and fast determination of homatropine hydrobromide in pharmaceutical formulation and urine was constructed. For the membrane preparation, homatropine-tetraphenylborate complexes were employed as electroactive materials in the membrane. The proposed sensor presents wide linear range $\left(10^{-5}-10^{-1} \mathrm{~mol} \mathrm{~L}^{-1}\right)$, low detection limit $\left(8 \times 10^{-6} \mathrm{~mol} \mathrm{~L}^{-1}\right)$, and fast response time (ca. $\left.10 \mathrm{~s}\right)$. Validation of the method shows suitability of the sensors for applicability in the quality control analysis of homatropine hydrobromide in pharmaceutical formulation and urine.

Keywords: potentiometric sensor, PVC membrane, homatropine hydrobromide, chemometrics, density functional based tight binding (DFTB)

\section{Introduction}

Homatropine (Equipin, Isopto Homatropine) (Figure 1) is an anticholinergic medication that inhibits muscarinic

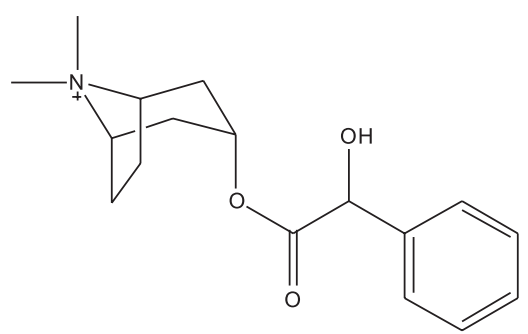

Figure 1. Chemical structure of homatropine hydrobromide.

*e-mail: ganjali@khayam.ut.ac.ir acetylcholine receptors and thus the parasympathetic nervous system. It is used in eye drops as a cycloplegic, to temporarily paralyze accommodation, and as a mydriatic, to dilate the pupil. Homatropine is less potent than atropine and has a shorter duration of action. It is available as the hydrobromide or methylbromide salt. ${ }^{1}$

There are several analytical methods for the assay of homatropine (HOM) in pharmaceutical and in biological fluids, such as capillary zone electrophoresis ${ }^{2,3}$ and high performance liquid chromatography (HPLC) ${ }^{4}$ and spectroscopy. ${ }^{5-7}$

Ion-selective electrodes are playing an important role in pharmaceutical analysis ${ }^{8-10}$ due to its simplicity, rapidity and accuracy over some other analytical methods like spectrophotometry and HPLC. Also, other mentioned methods are elaborated and time consuming, they involve 
the use of sophisticated equipment that might not be available in most analytical laboratories.

In this paper, interaction of homatropine with some ion-pair reagents was studied by theoretical and calculation methods. According to the obtained results a homatropine ion-selective potentiometric membrane electrode is developed based on ion-pair compound of homatropinetetraphenylbroate (HOM-TPB) as the electroactive substance. The proposed electrode was successfully applied for the determination of homatropine hydrobromide in pharmaceutical drops formulations and urine samples.

Computational chemistry and molecular modeling play an important role in the modern drug discovery. ${ }^{11-15}$ Computational work is also valuable in the drug development, where medium-sized organic pharmaceuticals are selected as candidates and are made in larger quantities. Instead of modeling interactions with macromolecules, the prediction of molecular properties for small molecules is more essential in the development stage. ${ }^{16}$

The strength of binding usually correlates with the target molecules tendency toward the ionophore, and several energy contributions may be responsible for the binding which is believed that amongst these energies, electrostatic interactions play a dominant role in the process at least in sequence preferences and the target molecules positioning. ${ }^{17,18}$

There are no literature studies to date that have used DFTB methods to evaluate drug selective ligands by electronic properties. The lack of work in this area is probably due to the inherent difficulties associated with doing calculations on a Drug-Ligand complex. Some of these problems include the lack of parameters for semiempirical or empirical methods, even though the numbers of atoms in typical drug complexes indicate the use of these lower level calculations would be appropriate.

In this study we use density functional theory (DFT) atomic population analysis to measure a Ligand-Drug complex by looking at the ability of the ligand to change in atomic charges and bond length of drug.

\section{Experimental}

\section{Apparatus}

The glass cell, where the homatropine-selective electrode was placed, consisted of an R684 model Analion $\mathrm{Ag} / \mathrm{AgCl}$ double junction reference electrode as the internal reference electrode and a double-junction saturated calomel electrode (SCE, Philips). The cell chamber was filled with an ammonium nitrate solution and both electrodes were connected to a Corning ion analyzer with a $250 \mathrm{pH} / \mathrm{mV}$ meter with $\pm 0.1 \mathrm{mV}$ precision.

\section{Materials and reagents}

The necessary chemicals (of analytical reagent grade) were: Sodium tetraphenyl borate (NaTBP), potassium tetrakis ( $p$-chlorophenyl) borate (KTpClPB), highmolecular weight polyvinylchloride (PVC), tetrahydrofuran (THF), dibutylphthalate (DBP), benzyl acetate (BA), nitrobenzene (NB) and the chloride and nitrate salts of the used cations (Merck Co.). Homatropine hydrobromide and its drops were obtained from different local pharmaceutical factories. All solutions were prepared using triply distilled deionized water.

Preparation of ion-pair compound of homatropinetetraphenylborate (HOM-TPB)

About $20 \mathrm{~mL}$ of $0.01 \mathrm{~mol} \mathrm{~L}^{-1}$ solution of homatropine hydrobromide were well mixed with $20 \mathrm{~mL}$ of $0.01 \mathrm{~mol} \mathrm{~L}^{-1}$ solution of tetraphenylborate under stirring. The resulting precipitate was filtered off, washed with water and dried.

\section{Preparation of the electrodes}

The general procedure to prepare the PVC membrane was as follow. Different amounts of the ion-pair along with appropriate amounts of PVC, plasticizer and additive were dissolved in tetrahydrofuran (THF), and the solution was mixed well. The resulting mixture was transferred into a glass dish of $2 \mathrm{~cm}$ diameter. The solvent was evaporated slowly until an oily concentrated mixture was obtained. A pyrex tube (3-5 mm o.d.) was dipped into the mixture for about $10 \mathrm{~s}$ so that a transparent membrane of about $0.3 \mathrm{~mm}$ thickness was formed. The tube was then pulled out from the mixture and kept at room temperature for about $10 \mathrm{~h}$. The tube was then filled with an internal filling solution $\left(1.0 \times 10^{-3} \mathrm{~mol} \mathrm{~L}^{-1}\right.$ homatropine hydrobromide). The electrode was finally conditioned for $24 \mathrm{~h}$ by soaking in a $1.0 \times 10^{-3} \mathrm{~mol} \mathrm{~L}^{-1}$ homatropine hydrobromide solution. ${ }^{19-21}$

\section{Standard homatropine hydrobromide solutions}

A stock solution of $10^{-1} \mathrm{~mol} \mathrm{~L}^{-1}$ homatropine hydrobromide was prepared by dissolving the calculated weight of the pure drug in $25 \mathrm{~mL}$ water. The working solutions $\left(10^{-5}\right.$ to $\left.10^{-1} \mathrm{~mol} \mathrm{~L}^{-1}\right)$ were prepared by serial appropriate dilution of the stock solution.

\section{The emf measurements}

The following cell was assembled for the conduction of the emf (electromotive force) measurements: 
$\mathrm{Ag}-\mathrm{AgCl} \mid$ internal solution, $10^{-3} \mathrm{~mol} \mathrm{~L}^{-1}$ homatropine hydrobromide | PVC membrane | sample solution | $\mathrm{Hg}_{-}$ $\mathrm{Hg}_{2} \mathrm{Cl}_{2}, \mathrm{KCl}$ (satd.)

These measurements were preceded by the calibration of the electrode with several homatropine hydrobromide solutions (working solutions).

\section{Computational methods}

Calculations on the isolated molecules and molecular complexes were performed within GAUSSIAN 98 package. ${ }^{22}$

Each species was initially optimized with PM3 method and then the optimized structures were again optimized with density functional theory using the $6-31 \mathrm{G}^{*}$ basis set. Full geometry optimizations and frequency calculations were performed and each species was found to be minima by having no negative values in the frequency calculation. The calculations gave internal energies at $0 \mathrm{~K}$. In order to obtain gas phase free energies at $298.15 \mathrm{~K}$, it is necessary to calculate the zero-point energies and thermal corrections together with entropies to convert the internal energies to Gibbs energies at $298.15 \mathrm{~K}^{23,24}$

Frequency calculations on these structures verified that they were true minima and provided the necessary thermal corrections to calculate $\mathrm{H}$ (Enthalpy) and G (Gibbs free energy). Finally, full optimizations and frequency calculations for each species were performed with the DFT/6-31G*. ${ }^{25,26}$

The other one-electron properties (dipole moment, polarizability, energies of the frontier molecular orbital) were also determined at the B3LYP/6-31G* level. For the charged species, the dipole moments were derived with respect to their mass center, once, for the non-neutral molecules, the calculated dipole moment depended on the origin of the coordinate system.

The stabilization energies of the selected complexes were determined with the help of the DFT calculations, and calculated with a recently introduced method, based on the combination of the approximate tight-binding DFTB with the empirical dispersion energy. The DFT methods are known to be inherently very deficient for stacking interactions, as they basically ignore the dispersion attraction..$^{27-29}$ As a consequence, their enlargement by an empirical dispersion term currently appears to be a very reasonable way to improve the major deficiency of the DFT method for the evaluation of the molecular complexes. It should also be mentioned that the interaction energies were obtained as the difference between the complex energy and the combined energies of the molecules in isolation. ${ }^{30}$

\section{Results and Discussion}

\section{Theoretical study}

Molecular parameters are controlled by the molecular geometry. Therefore, geometry optimization is the most important step for the calculation of the interaction energy. The optimized geometries and numeration of the atoms of the studied molecules, L1 for NaTPB, L2 for KTpCIPB, HOM for Drug, Drug-L1 for HOM-TPB and Drug-L2 for HOM-TpClPB, are presented in Figures 2 to 6 , respectively.

To obtain a clue on homatropine tendency for L1 and L2 as potential ion-exchanger, DFTB calculations (B3LYP/ $\left.6-31 G^{*}\right)$ were carried out. The pair wise interaction energy $\Delta \mathrm{E}_{\mathrm{A}-\mathrm{B}}$ between molecules A (L1 or L2) and B (the drug)

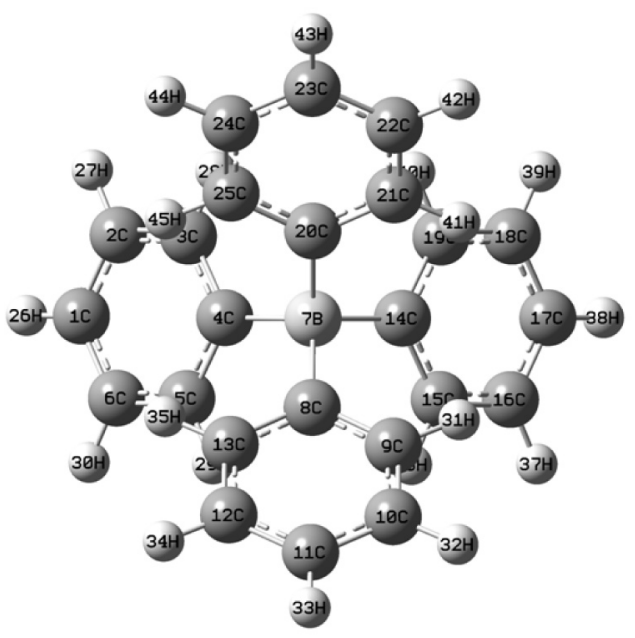

Figure 2. The full optimized structure of L1.

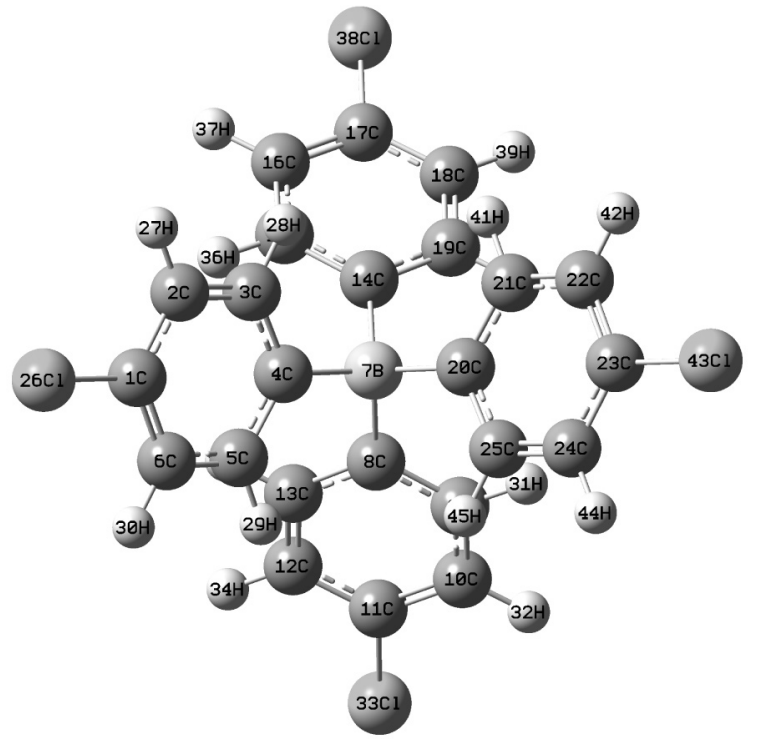

Figure 3. The full optimized structure of L2. 
was estimated as the difference between the energy of the formed complex and the energies of the isolated partners.

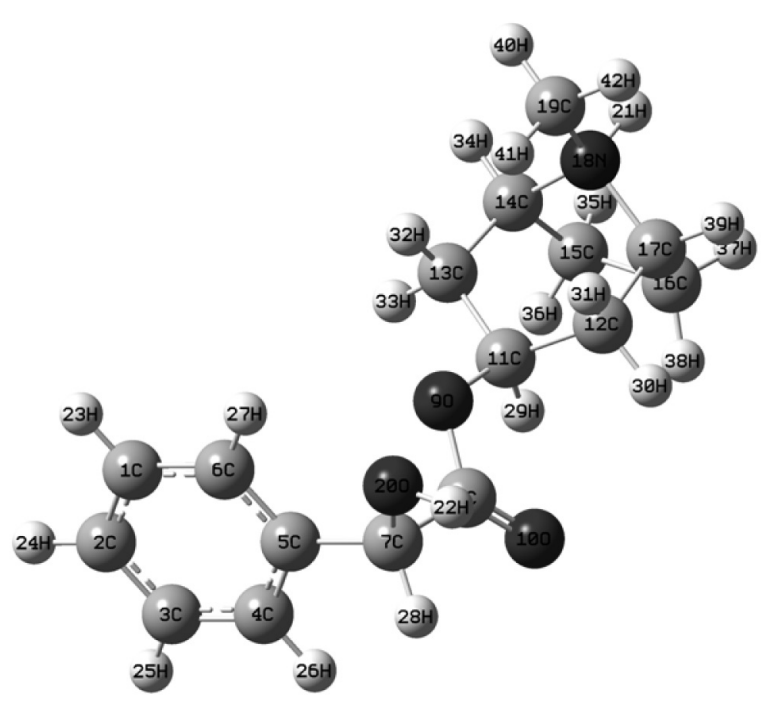

Figure 4. The full optimized structure of HOM.
The interaction energies were corrected for the basis set superposition error using the counterpoise method, ${ }^{31,32}$

$\Delta \mathrm{E}_{\mathrm{A}-\mathrm{B}}=\mathrm{E}_{\mathrm{A}-\mathrm{B}}-\mathrm{E}_{\mathrm{A}}-\mathrm{E}_{\mathrm{B}}$

which led to the values of -66.117 and $-55.221 \mathrm{Kcal} \mathrm{mol}^{-1}$ for $\Delta \mathrm{E}_{\mathrm{L} 1}$ and $\Delta \mathrm{E}_{\mathrm{L} 2}$ respectively, thus indicating $\mathrm{L} 1$ as a more appropriate ionophore for homatropine sensor in comparison to L2, due to its higher interaction energy.

Results presented in Table 1 show that interactions existing between the drug and L1 are mostly electrostatic. Charge changes in the ion pairs are localized on specific atoms that interact together in each molecule. ${ }^{33-36}$ As can be seen, all heteroatoms ( $\mathrm{N}$ and $\mathrm{O}$ ) charge changes confirm the effective roles of hydrogen bonding and electrostatic interactions in ion pair formation. Bond lengths and atomic charges have changed as a result of ion pair formation, and the most noticeable atomic charge changes are shown in Table 1. According to Table 1, interactions between the drug and the studied ligands concern to N18 and B results

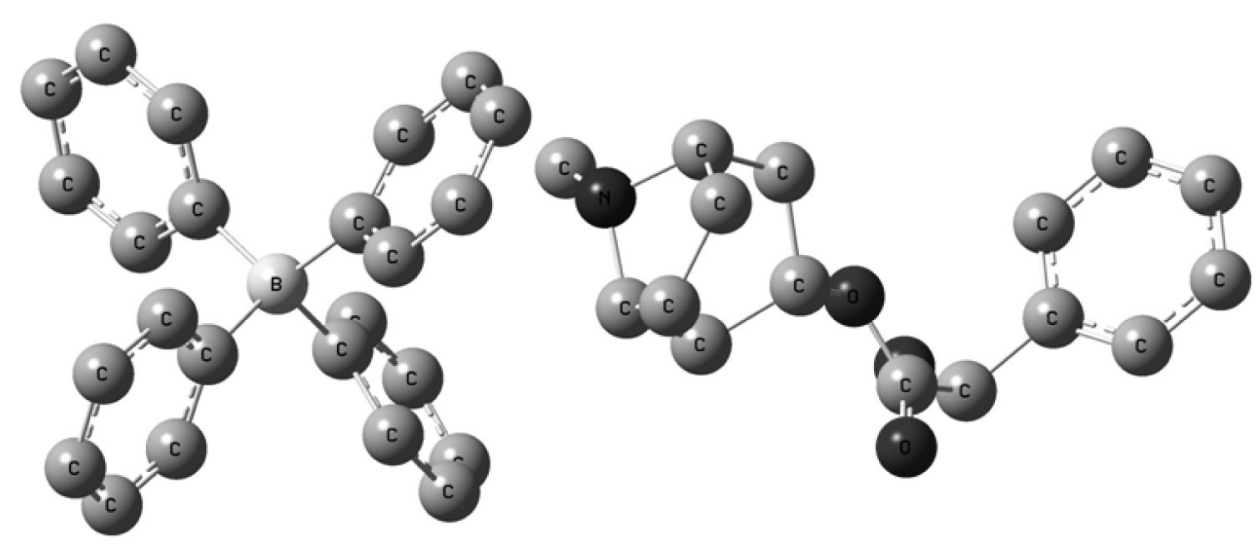

Figure 5. The full optimized structure of L1-HOM complex.

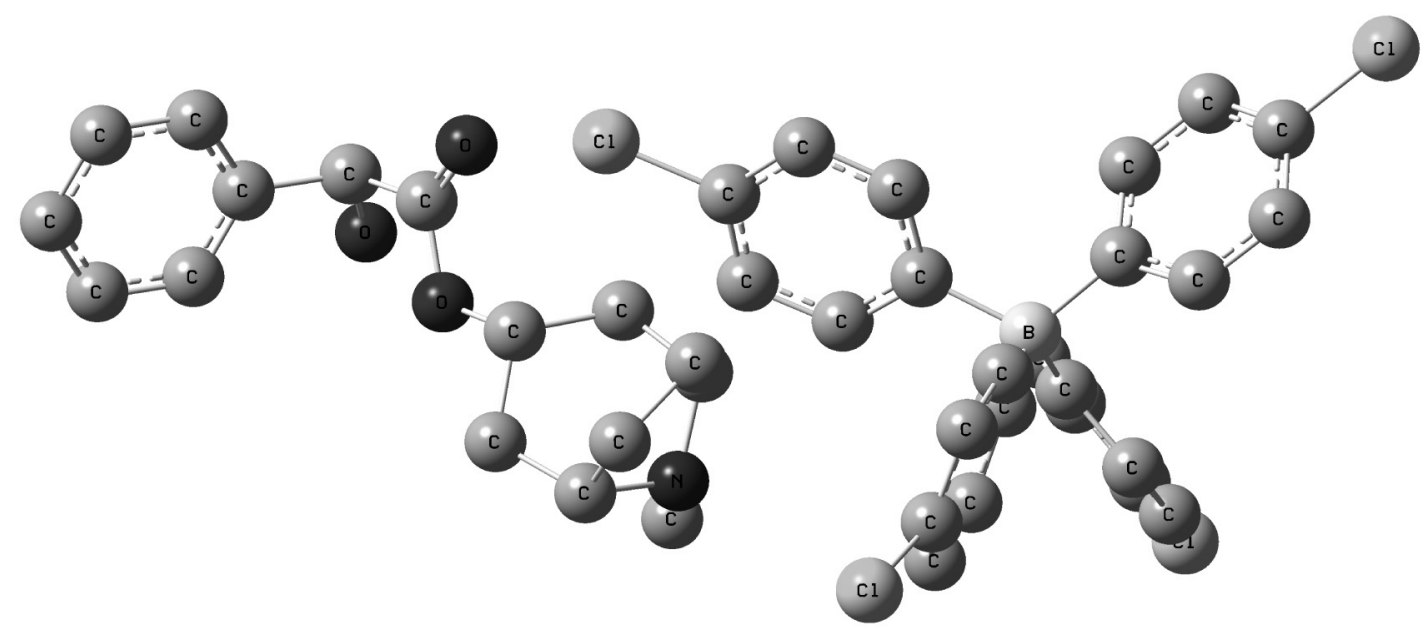

Figure 6. The full optimized structure of L2-HOM complex. 
Table 1. Computed atomic charges and bond lengths $(\AA)$ for homatropine, $\mathrm{L} 1$ and $\mathrm{L} 2$ before and after the complex formation

\begin{tabular}{lccc}
\hline charges & homatropine & HOM-L1 & HOM-L2 \\
\hline O19 & -0.250 & -0.253 & -0.251 \\
O10 & -0.258 & -0.259 & -0.259 \\
C14 & 0.067 & 0.064 & 0.066 \\
C17 & 0.068 & 0.061 & 0.069 \\
$\mathrm{~N} 18$ & -0.227 & -0.235 & -0.229 \\
$\mathrm{C} 19$ & -0.085 & -0.091 & -0.087 \\
$\mathrm{O} 20$ & -0.276 & -0.274 & -0.275 \\
$\mathrm{H} 21$ & 0.270 & 0.292 & 0.275 \\
$\mathrm{H} 22$ & 0.187 & 0.184 & 0.186 \\
$\mathrm{H} 23$ & 0.069 & 0.067 & 0.068 \\
\hline bond & homatropine & HOM-L1 & HOM-L2 \\
\hline $\mathrm{R}(7.8)$ & 1.560 & 1.567 & 1.561 \\
$\mathrm{R}(7.20)$ & 1.435 & 1.434 & 1.434 \\
$\mathrm{R}(7.28)$ & 1.097 & 1.098 & 1.097 \\
$\mathrm{R}(8.9)$ & 1.403 & 1.397 & 1.401 \\
$\mathrm{R}(8.10)$ & 1.214 & 1.215 & 1.215 \\
$\mathrm{R}(9.11)$ & 1.436 & 1.440 & 1.439 \\
$\mathrm{R}(11.29)$ & 1.095 & 1.094 & 1.094 \\
$\mathrm{R}(14.18)$ & 1.540 & 1.530 & 1.538 \\
$\mathrm{R}(14.34)$ & 1.093 & 1.092 & 1.092 \\
$\mathrm{R}(17.18)$ & 1.541 & 1.533 & 1.539 \\
$\mathrm{R}(17.39)$ & 1.093 & 1.093 & 1.093 \\
$\mathrm{R}(18.19)$ & 1.517 & 1.513 & 1.515 \\
$\mathrm{R}(18.21)$ & 1.040 & 1.066 & 1.045 \\
$\mathrm{HOMO}$ & -9.530 & 2.772 for L1 & -3.841 for L2 \\
$\mathrm{LUMO}$ & 3.480 & 10.940 for L1 & 9.613 for L2 \\
\hline & & &
\end{tabular}

in the occurrence of the most significant changes in the atomic charges and also bond lengths of those atoms that are bonded to them. For example, for the drug, H21 atomic charge changed from 0.270 to 0.291 along with its bond length (N18-H21), which shifted from 1.040 to 1.066 . Furthermore, atomic charge changes and bond lengths in $\mathrm{L} 1$ are more remarkable for boro (from 0.232 to 0.027 ) and its connected carbon atoms. A similar study was also done on the results obtained for L2. In accordance to Table 1, the computed atomic charges and bond lengths for $\mathrm{L} 2$ are not as remarkable as those of $\mathrm{L} 1$.

High values of polarizability (148.545 and 94.953 for L1 and drug, respectively) prove its effect role on interactions amongst $\mathrm{L} 1$ and the drug. While the low values of dipole-dipole interactions (especially for that of $\mathrm{L} 1=0.0$ and for drug $=1.1 \mathrm{D}$ ) show that it does not play a significant role between L1 and the studied drug. Moreover, the higher polarizability value of L1 to that of L2 (121.101) results in a stronger dispersion interaction between $\mathrm{L} 1$ and the drug.

Additionally, since the studied molecules are in form of ions, electrostatic interactions should also be considered. The highest occupied molecular orbital (HOMO) and the lowest unoccupied molecular orbital (LUMO) for L1, L2 and the drug were calculated at the B3LYP/6-31G(d) level, and are presented in Table 1. The eigenvalues of LUMO and HOMO and their energy gap reflect the chemical activity of the molecule. LUMO as an electron acceptor represents the ability to capture an electron, while HOMO as an electron donor represents the ability to donate an electron. From Table 1, the results confirm that charge transfer interaction is more noticeable between L1 and the drug in comparison to that of $\mathrm{L} 2$, which is attributed to the HOMO energy of L1 being closer to LUMO energy of the drug.

Membrane composition effect on the potential response of the sensor

The potential response of a sensor is greatly related to the membrane ingredients. As a result, the influence of membrane composition on the potential responses of the homatropine sensor was studied. For this purpose, different membrane compositions as shown in Table 2 were tested. It can be seen that the membrane with the composition of 30\% PVC, 5\% HOM-TPB, and 65\% DBP

Table 2. Optimization of membrane ingredients

\begin{tabular}{|c|c|c|c|c|c|c|c|}
\hline Membrane No. & $\begin{array}{l}\text { Additive / } \\
\text { (wt. } \% \text { ) }\end{array}$ & $\begin{array}{c}\text { Ion-pair / } \\
\text { (wt.\%) }\end{array}$ & $\begin{array}{l}\text { Plasticizer / } \\
\text { (wt.\%) }\end{array}$ & $\begin{array}{l}\mathrm{PVC} / \\
\text { (wt.\%) }\end{array}$ & $\begin{array}{l}\text { Detection Limit / } \\
\quad\left(\mathrm{mol} \mathrm{L}^{-1}\right)\end{array}$ & $\begin{array}{l}\text { Linear range / } \\
\left(\mathrm{mol} \mathrm{L}^{-1}\right)\end{array}$ & $\begin{array}{c}\text { Slope / } \\
\left(\mathrm{mV} \mathrm{decade}^{-1}\right)\end{array}$ \\
\hline 1 & - & 4 & DBP, 65 & 30 & $7 \times 10^{-6}$ & $1.0 \times 10^{-5}-1.0 \times 10^{-1}$ & 56.7 \\
\hline 2 & - & 5 & DBP, 64 & 30 & $8 \times 10^{-6}$ & $1.0 \times 10^{-5}-1.0 \times 10^{-1}$ & 57.7 \\
\hline 3 & - & 6 & DBP, 63 & 30 & $7 \times 10^{-6}$ & $1.0 \times 10^{-5}-1.0 \times 10^{-1}$ & 55.2 \\
\hline 4 & 2, NaTPB & 5 & DBP, 62 & 30 & $3.0 \times 10^{-4}$ & $5.0 \times 10^{-4}-1.0 \times 10^{-2}$ & 55.9 \\
\hline 5 & 3, NaTPB & 5 & DBP, 63 & 30 & $6.0 \times 10^{-5}$ & $1.0 \times 10^{-4}-5.0 \times 10^{-2}$ & 53.4 \\
\hline 6 & - & 5 & $\mathrm{NB}, 65$ & 30 & $4.0 \times 10^{-4}$ & $5.0 \times 10^{-4}-1.0 \times 10^{-2}$ & 20.4 \\
\hline 7 & - & 5 & BA, 65 & 30 & $3.0 \times 10^{-4}$ & $5.0 \times 10^{-3}-1.0 \times 10^{-2}$ & 15.3 \\
\hline 8 & - & 5 & DBP, 65 & 30 & $6.0 \times 10^{-6}$ & $1.0 \times 10^{-5}-1.0 \times 10^{-2}$ & 48.6 \\
\hline
\end{tabular}


(No. 2), was the optimum one in the development of this sensor. This membrane composition was selected after many considerations.

The high homatropine extraction into the liquid membrane was a result of the elevated ion-pair tendency to exchange with the homatropine cations. From Table 2, $5 \mathrm{mg}$ ion-pair (HOM-TPB) is the best amount for the best response.

Also, HOM-TpClPB was used as an ion-pair in membrane composition. According to the theoretical calculations, interaction between homatropine and TpCIPB anion is not so strong. The experimental data support the theoretical data.

The second factor that helps homatropine ions to be extracted from an aqueous solution into the membrane as an organic phase is plasticizer. After the evaluation of three solvent mediators (NB, BA and DBP), it was observed that they have not the same results if the optimum composition is used. DBP, which is a low-polar solvent mediator, shows better response than BA and NB. NB and BA have higher dielectric constant values than DBP, leading to the extraction of the polar ions, which have negative effects on the extraction of the homatropine ions as a hydrophobic ion.

The presence of lipophilic anions in a cation-selective membrane was also considered. As can be deduced from Table 2, the presence of such anions in a cation-selective membrane, which is based on an ion-pair, decreases the response behavior of the sensor.

\section{pH Effect on the electrode response}

In an approach to understand the impact of $\mathrm{pH}$ on the electrode response, the potential was measured at two particular concentrations of the homatropine solution $\left(1.0 \times 10^{-4} \mathrm{~mol} \mathrm{~L}^{-1}\right)$ from the $\mathrm{pH}$ value of 2.0 up to 12.0 (concentrated $\mathrm{NaOH}$ or $\mathrm{HCl}$ solutions were employed

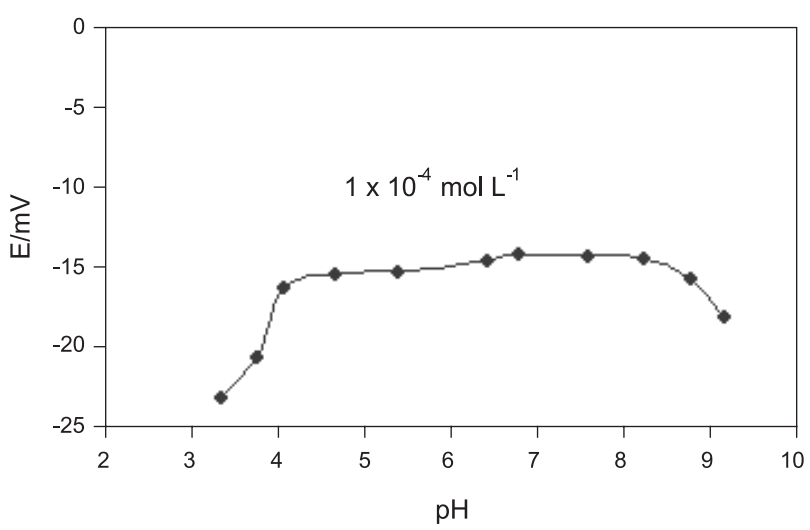

Figure 7. The $\mathrm{pH}$ effect of the test solutions $\left(1.0 \times 10^{-4} \mathrm{~mol} \mathrm{~L}^{-1}\right)$ on the potential response of the homatropine sensor with the composition of the membrane No. 2 . for the $\mathrm{pH}$ adjustment). As it can be seen from Figure 7, the potential remained constant despite the $\mathrm{pH}$ change in the range of 4.0 to 8.0 , indicating the applicability of this electrode in the specific $\mathrm{pH}$ range.

On the contrary, relatively noteworthy fluctuations in the potential $v s$. pH behavior took place below and above the formerly stated $\mathrm{pH}$ limits. In detail, the fluctuations above the $\mathrm{pH}$ value of 8.0 might be justified by removing the positive charge on the drug molecule and the fluctuations below the $\mathrm{pH}$ value of 4.0 were attributed to removing the ion-pair in the membrane.

\section{Study of sensor properties}

The properties of a potentiometric membrane sensor are characterized by parameters such as measuring range, detection limit, response time, selectivity, lifetime and accuracy.

\section{Measuring range}

The measuring range of an ion-selective electrode includes the linear part of the calibration graph as shown in Figure 8. Measurements can be performed in this lower range, but it must be noted that more closely spaced calibration points are required for more precise determinations. According to another definition, the measuring range of an ion-selective electrode is defined as the activity range between the upper and lower detection limits. The applicable measuring range of the proposed sensor is between $1 \times 10^{-5}$ and $1 \times 10^{-1} \mathrm{~mol} \mathrm{~L}^{-1}$.

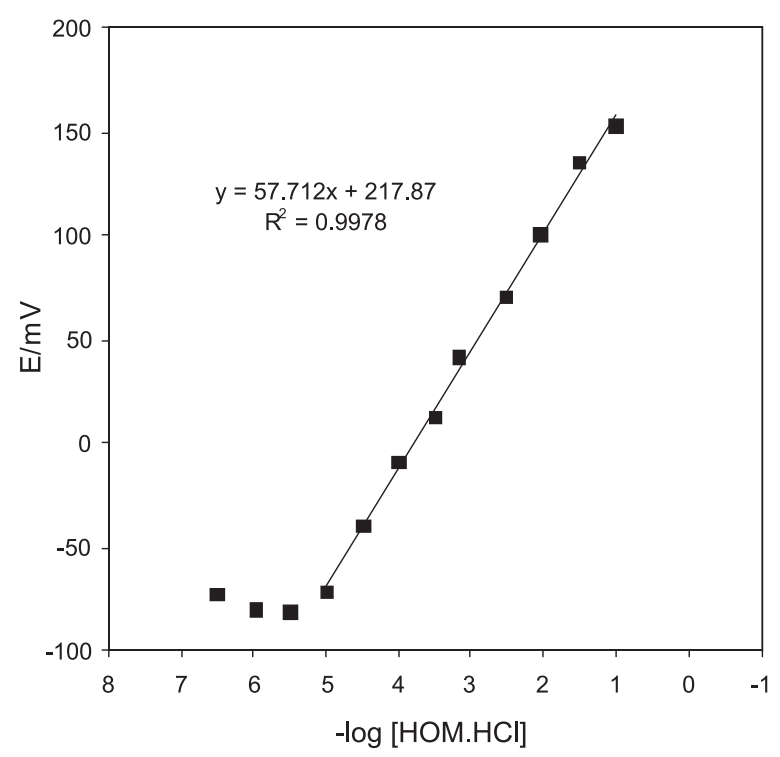

Figure 8. Calibration curve of the homatropine membrane sensor with the composition of the membrane No. 2. The results are based on 8 measurements. 


\section{Detection limit}

By extrapolating the linear parts of the ion-selective calibration curve, the detection limit of an ion-selective electrode can be calculated. In practice, detection limits for the most selective electrodes are in the range of $10^{-5}-10^{-6} \mathrm{~mol} \mathrm{~L}^{-1}$.

In this work, the detection limit of the proposed membrane sensor was $8 \times 10^{-6} \mathrm{~mol} \mathrm{~L}^{-1}$. It was calculated by extrapolating the two segments of the calibration curve (Figure 8).

\section{Response time}

The response time of an electrode is evaluated by measuring the average time required to achieve a potential within $\pm 0.1 \mathrm{mV}$ of the final steady-state potential, upon successive immersion of a series of interested ions, each having a ten-fold difference in concentration. It is notable that the experimental conditions like: the stirring or flow rate, the ionic concentration of the test solution, the concentration of the conditioning solution, any previous usages or preconditioning of the electrode, and the testing temperature have an impact on the experimental response time of a sensor. ${ }^{8}$

In this work, less than $10 \mathrm{~s}$ response times were obtained for the proposed electrode when contacting different homatropine solutions from $1.0 \times 10^{-5}$ to $1.0 \times 10^{-1} \mathrm{~mol} \mathrm{~L}^{-1}$.

\section{Homatropine $\mathrm{HBr}$ electrode selectivity}

The selectivity of an ion-pair based membrane electrode depends on the physico-chemical characteristics of the ion-exchange process at the membrane-sample solution interface, on the mobility of the respective ions in the membrane and on the hydrophobic interactions between the primary ion and the organic membrane.

The selectivity of the homatropine $\mathrm{HBr}$ membrane electrode is related to the free energy of transfer of the homatropine $\mathrm{HBr}$ cation between aqueous and organic phases. The response of the electrode towards different substances has been checked and the selectivity coefficient values $\mathrm{K}_{\mathrm{AB}}^{\mathrm{Pot}}$ were used to evaluate the interference degree. The selectivity coefficient values were obtained using the matched potential method (MPM). ${ }^{37}$

The steps that need to be followed for the MPM method are: (i) The addition of a specified activity (concentration) of the primary ions (A, $10^{-2} \mathrm{~mol} \mathrm{~L}^{-1}$ of homatropine solution) to a reference solution $\left(10^{-5} \mathrm{~mol} \mathrm{~L}^{-1}\right.$ of homatropine solution), (ii) The potential measurement. In addition, another experiment is conducted separately. For that experiment, the interfering ions $\left(\mathrm{B}, 10^{-2} \mathrm{~mol} \mathrm{~L}^{-1}\right)$ are consecutively added to an identical reference solution, until the measured potential matches the one obtained before the addition of the primary ions. Then, the selectivity coefficient, as defined by the matched potential method, $\mathrm{K}_{\mathrm{MPM}}$, is equal to the ratio of the resulting primary ion activity (concentration) to the interfering ion activity, $\mathrm{K}_{\mathrm{MPM}}=\mathrm{a}_{\mathrm{A}} / \mathrm{a}_{\mathrm{B}}$.

The respective results are summarized in Table 3, depicting that the selectivity coefficient values of the electrode for all the tested substances were in the order of $10^{-3}$ or smaller. Given the low coefficient values, it was considered that the function of the homatropine-selective membrane sensor would not be greatly disturbed.

Table 3. Selectivity coefficients of various interfering compounds for homatropine sensor

\begin{tabular}{lc}
\hline Interference & $\log \mathrm{K}_{\mathrm{MPM}}$ \\
\hline $\mathrm{Na}^{+}$ & -3.44 \\
$\mathrm{Cl}^{-}$ & -3.35 \\
$\mathrm{Br}^{-}$ & -3.64 \\
$\mathrm{I}^{-}$ & -3.21 \\
$\mathrm{CO}_{3}{ }^{2-}$ & -2.75 \\
$\mathrm{NO}_{3}{ }^{-}$ & -3.78 \\
$\mathrm{Mg}^{2+}$ & -3.24 \\
$\mathrm{HPO}_{4}^{2-}$ & -3.10 \\
$\mathrm{Ca}^{2+}$ & -3.02 \\
$\mathrm{~K}^{+}$ & -2.64 \\
$\mathrm{Glucose}^{+}$ & -3.20 \\
Amonium & -3.43 \\
\hline
\end{tabular}

\section{Lifetime}

The average lifetime for most of the reported ionselective sensors is in the range of 4-10 weeks. After this time the slope of the sensor will decrease, and the detection limit will increase. The sensors were tested for 10 weeks, during which time the electrodes were used extensively (one hour per day). The proposed sensors can be used for six weeks. First, there is a slight gradual decrease in the slopes (from 57.7 to $54.3 \mathrm{mV}$ decade ${ }^{-1}$ ) and then, an increase in the detection limit (from $8.0 \times 10^{-6} \mathrm{~mol} \mathrm{~L}^{-1}$ to $1.5 \times 10^{-4} \mathrm{~mol} \mathrm{~L}^{-1}$ ). It is well established that the loss of plasticizer, ionic site from the polymeric film is due to leaching in the sample, and is a primary reason for limited lifetimes of the sensors.

\section{Analytical application}

\section{Determination of homatropine in formulations}

An appropriate amount of homotropine drop $(5 \mathrm{~mL})$ was transferred into a $10 \mathrm{~mL}$ volumetric flask. The solution was then diluted to the mark with water and the proposed electrode determined homatropine content by using the 
calibration method. The results for determination of homatropine amount in some pharmaceutical samples from local pharmacy are shown in Table 4. As it is seen, the results are in satisfactory agreement with the stated content on eye drop.

Table 4. Results of homatropine assay in drops by the homatropine membrane sensor

\begin{tabular}{lcc}
\hline Application sample (mg per10mL) & $\begin{array}{c}\text { Stated content } \\
(\mathrm{mg} \text { per10 } \mathrm{mL}) *\end{array}$ & Found \\
\hline $\begin{array}{l}\text { Homatropine HBr OPH drop, } \\
\text { Sina Company }\end{array}$ & $2 \%$ & $2.03 \%$ \\
\hline
\end{tabular}

*Data obtained from three measurements.

\section{Recovery of homatropine from urine samples}

In order to investigate the applicability of the new sensor for determination of the drug in biological fluids, it was applied to the recovery of homatropine from urine samples. A $2.5 \mathrm{~mL}$ of $10^{-3} \mathrm{~mol} \mathrm{~L}^{-1}$ homatropine solution was transferred into a $10 \mathrm{~mL}$ volumetric flask. After addition of a $2.5 \mathrm{~mL}$ of urine samples, the solution was diluted to the mark with water. The mentioned electrode was then used to determine the homatropine content using the calibration technique. The recovery from three replicate measurements was found to be $103.5 \%, 104.4 \%$ and $105.1 \%$, respectively.

\section{Validation of the method}

The linearity, limit of detection, precision, accuracy, and ruggedness/robustness were the parameters, which were used for the method validation.

As mentioned before, the measuring range of the homatropine sensor is between $1 \times 10^{-5}$ and $1 \times 10^{-1} \mathrm{~mol} \mathrm{~L}^{-1}$. The detection limit of the sensor was calculated $8.0 \times 10^{-6} \mathrm{~mol} \mathrm{~L}^{-1}\left(3 \mu \mathrm{g} \mathrm{mL} \mathrm{m}^{-1}\right)$.

\section{Precision}

The parameters of the repeatability and reproducibility were investigated in order to assess the precision of the technique. For the repeatability monitoring, 10 replicate standard samples, $3,30,300 \mu \mathrm{g} \mathrm{mL}^{-1}$ were measured. Then, the mean concentrations were found to be, 3.03, $30.5,303.2 \mu \mathrm{g} \mathrm{mL}^{-1}$ and with associated RSD values of $1.4,1.04$, and $0.42 \%$, respectively. Regarding the inter-day precision, the same three concentrations were measured for 3 consecutive days, providing mean homatropine concentrations of $3.02,30.5,303.5 \mu \mathrm{g} \mathrm{mL}^{-1}$ and associated RSD values of $1.82,1.02$, and $0.26 \%$, respectively.

\section{Accuracy}

The relevant error percentage and accuracy were calculated in each above case. The resultant concentrations were $3.02 \pm 0.04,30.5 \pm 0.4$, and $303.5 \pm 1.3 \mu \mathrm{g} \mathrm{mL}-1$ with relevant error percentages of $3.82,1.24$, and $0.36 \%$, respectively.

\section{Ruggedness/Robustness}

For ruggedness of the method, a comparison was performed between the intra- and inter-day assay results for homatropine obtained by two analysts. The RSD values for the intra- and inter-day assays of homatropine in the cited formulations performed in the same laboratory by the two analysts did not exceed $2.5 \%$. On the other hand, the robustness was examined while the parameter values $(\mathrm{pH}$ of the eluent and the laboratory temperature) were slightly varied. Homatropine recovery percentages were good under most conditions, not showing any significant change when the critical parameters were modified.

\section{Conclusions}

In the presented paper, types of interactions existing between a drug and ligands were studied. Since the studied molecules were in form of ions that resulted in ion pair formation, the DFTB method also considers dispersion energies in addition to those calculated using DFT, was used for further investigations. These theoretical calculations help selecting appropriate ionophores and also predicting their selectivity for different drugs. After a series of experiments involving the usage of H-TPB ion-pair complexes along with several plasticizers in the membrane design, it was concluded that the homatropine sensor exhibited excellent analytical performance characteristics. It demonstrated an advanced performance with a fast response time ( $c a$. $10 \mathrm{~s}$ ), a lower detection limit of $8.0 \times 10^{-6} \mathrm{~mol} \mathrm{~L}^{-1}$ and $\mathrm{pH}$ independent potential responses across the range of 4.0-8.0. This high sensitivity of the sensor enabled the homatropine determination in pharmaceutical analysis.

The theoretical calculations are very accurate and suitable methods for obtaining interaction energies and therefore choosing a better ion-pair. Additionally, by employing these methods, one can find the center of interactions in the target molecule and ionophore.

\section{List of Abbreviation}

BA, benzyl acetate; DBP, dibutylphthalate; DFT, Density Functional Theory; DFTB, Density Functional based Tight Binding; HOM, homatropine; HOMO, highest occupied molecular orbital; HOM-TPB, homatropinetetraphenylbroate; HOM-TpCIPB, homatropine-tetrakis ( $p$-chlorophenyl) borate; HPLC, high performance liquid chromatography; $\mathrm{KTpClPB}$, potassium tetrakis 
( $p$-chlorophenyl) borate; LUMO, lowest unoccupied molecular orbital; NaTBP, sodium tetraphenyl borate; NB, nitrobenzene; PVC, polyvinylchloride; THF, tetrahydrofuran.

\section{Acknowledgment}

The authors are grateful to the Research Council of University of Tehran for the financial support of this work.

\section{References}

1. http://en.wikipedia.org/wiki/homatropine, accessed in October 2008.

2. Larissa, S. C.; Oldair D. L.; Orlando F.-F.; Talanta 2005, 69, 239.

3. Cherkaoui, S.; Mateus, L.; Christen, P.; Veuthey, J. L.; J. Chromatogr., B: Anal. Technol. Biomed. Life Sci. 1997 696, 283.

4. Collins, A. J.; Campbell, A. T.; Bain, R.; J. Clin. Pharm. Ther. 1997, 4, 205.

5. Millership, J. S.; J. Pharm. Biomed. Anal. 1995, 13, 795.

6. Joseph, A. F.; Bruce, J. R.; J. Pharm. Sci. 2006, 59, 1646.

7. Lester, C.; Robert, E. D.; J. Pharm. Sci. 2006, 57, 1977.

8. Ganjali, M. R.; Norouzi, P.; Rezapour, M.; Encyclopedia of Sensors, Potentiometric Ion Sensors, American Scientific Publisher (ASP): Los Angeles, 2006, Vol. 8, pp. 197-288.

9. Faridbod, F.; Ganjali, M. R.; Dinarvand, R.; Norouzi, P.; Combinatorial Chemistry \& High Throughput Screening 2007, 10, 527.

10. Ganjali, M. R.; Norouzi, P.; Faridbod, F.; Pirelahi, H.; J. Chin. Chem. Soc. 2007, 54, 55

11. Ripka, W. C.; Vlasuk, G. P.; Annu. Rep. Med. Chem. 1997, 32, 71.

12. Riahi, S.; Ganjali, M. R.; Norouzi, P.; Jafari, F.; Sens. Actuators, B 2008, 132, 13.

13. Riahi, S.; Moghaddam, A. B.; Ganjali, M. R.; Norouzi, P.; Spectrochim. Acta, Part A 2008, 71, 1390.

14. Riahi, S.; Ganjali, M. R.; Moghaddamb, A. B.; Norouzi, P.; Hosseiny Davarani, S. S.; Spectrochim. Acta, Part A 2008, 70, 94.

15. Riahi, S.; Norouzi, P.; Moghaddam, A. B.; Ganjali, M. R.; Karimipour, G. R.; Sharghi, H.; Chem. Phys. 2007, 337, 33.

16. Chirikjian, G. S.; Comput. Theor. Polym. Sci. 2001, 11, 143.

17. Riahi, S.; Ganjali, M. R.; Dinarvand, R.; Karamdoust, S.; Bagherzadeh, K.; Norouzi, P.; Chem. Biol. Drug Des. 2008 , 71,474 .
18. Riahi, S.; Ganjali, M. R.; Norouzi, P.; J. Theor. Comput. Chem. 2008, 7, 317 .

19. Zamani, H. A.; Ganjali, M. R.; Pooyamanesh, M. J.; J. Braz. Chem. Soc. 2006, 17, 149.

20. Norouzi, P.; Ganjali, M. R.; Ahmadalinezhad, A.; Adib, M.; J. Braz. Chem. Soc. 2006, 17, 1309.

21. Ganjali, M. R.; Norouzi, P.; Alizadeh, T.; Adib, M.; J. Braz. Chem. Soc. 2006, 17, 1217.

22. Frisch, M. J.; Trucks, G. W.; Schlegel, H. B.; Scuseria, G. E.; Robb, M. A.; Cheeseman, J. R.; Zakrzewski, V. G., Ortiz, J. V.; Foresman, J. B.; Cioslowski, J.; Stefanov, B. B.; Nanayakkara, A.; Challacombe, M.; Peng, C. Y.; Ayala, P. Y.; Chen, W.; Wong, M. W.; Andres, J. L.; Replogle, E. S.; Gomperts, R.; Martin, R. L.; Fox, D. J.; Head-Gordon, M.; Gonzalez, C.; Pople, J.A.; Gaussian Inc., Pittsburgh, PA, 1998.

23. Stewart, J. J. P.; J. Comp. Chem. 1989, 10, 210.

24. Stewart, J. J. P.; J. Comp. Chem. 1989, 10, 221.

25. Yang, W.; Wu, Q.; Phys. Rev. Lett. 2002, 89, 143002.

26. Parr, R. G.; Yang, W; Аnnu. Rev. Phys. Chem. 1995, 46, 701.

27. Duijneveldt, F. B.; Duijneveldt-van de, Rijdt J. G. C. M.; Lenthe J. H.; Chem. Rev. 1994, 94, 1873.

28. Nieaus, T. A.; Elstner, M.; Frauenheim, T.; Suhai, S.; THEOCHEM 2001, 541, 185.

29. Zhou, H. Y.; Tajkhorshid, E.; Frauenheim, T.; Suhai, S.; Elstner, M.; Chem. Phys. 2002, 277, 91.

30. Hobza, P.; Zahradnik, R.; Intermolecular Complexes, Elsevier: Amsterdam, 1988

31. Frisch, M. J.; Del Bene, J. E.; Binkley, J. S.; Schaefer, H. F.; J. Chem. Phys. 1986, 84, 2279.

32. Schwenke, D. W.; Truhlar, D. G.; J. Chem. Phys. 1985, 82, 2418.

33. Ganjali, M. R. ; Norouzi, P.; Faridbod, F.; Riahi, S.; Ravanshad, J.; Tashkhourian, J.; Salavati-Niasari, M.; Javaheri, M.; IEEE Sens. J. 2007, 7, 544.

34. Ganjali, M. R.; Norouzi, P.; Sadat Mirnaghi, F.; Riahi, S.; Faridbod, F.; IEEE Sens. J. 2007, 7, 544.

35. Faridbod, F.; Ganjali, M. R.; Dinarvand, R.; Norouzi, P.; Riahi, S.; Sensors 2008, 8, 1645 .

36. Ganjali, M. R.; Norouzi, P.; Faridbod, F.; Riahi, S.; Yaftian, M. R.; Zamani, A.; Matt, D.; J. Appl. Electrochem. 2007, 37, 827.

37. Buck, P. R.; Lindner, E.; Pure Appl. Chem. 1994, 66, 2527.

Received: August 27, 2008

Web Release Date: April 17, 2009 